\title{
Relationship between fetal growth and the development of asthma and atopy in childhood
}

\author{
Philip Leadbitter, Neil Pearce, Soo Cheng, Malcolm R Sears, M David Holdaway, \\ Erin M Flannery, G Peter Herbison, Richard Beasley
}

Wellington Asthma

Research Group,

Department of

Medicine, Wellington

School of Medicine,

P.O. Box 7343 ,

Wellington, New

Zealand

P Leadbitter

N Pearce

S Cheng

R Beasley

Firestone Regional

Chest and Allergy

Unit, St Joseph's

Hospital-McMaster

University, Hamilton,

Ontario L8N4A6,

Canada

M R Sears

Department of

Paediatrics

M D Holdaway

Department of

Medicine

E M Flannery

Department of

Preventive Medicine

G P Herbison

Otago Medical School, P.O. Box 913, Dunedin, New Zealand

Correspondence to:

Dr P Leadbitter.

Received 4 January 1999

Returned to authors

29 March 1999

Revised manuscript received

15 June 1999

Accepted for publication

1 July 1999

\begin{abstract}
Background-A study was undertaken to investigate the relationship between birth anthropometric measures and the subsequent development of asthma, airway hyperresponsiveness, and atopy in later childhood.
\end{abstract}

Methods-A longitudinal study was performed on 734 subjects (71\%) from a cohort of children born in Dunedin, New Zealand in 1972-73. The birth anthropometric measures were available from hospital records and the main outcome measures of reported asthma, skin prick tests, and methacholine hyperresponsiveness were measured at the age of 13 years, while the serum total IgE was measured at 11 years.

Results-After adjustment for other factors, infants with a larger head circumference at birth tended to have higher serum total IgE at 11 years of age $(p=0.02)$ but IgE was not associated significantly with birth length or birth weight. The adjusted odds ratio for raised serum IgE ( $>150$ IU/ $\mathrm{ml}$ ) in infants with a head circumference of $37 \mathrm{~cm}$ or more was $3.4(95 \%$ CI 1.4 to $7.9)$. In contrast, recent asthma symptoms were positively associated with birth length $(p=0.04)$ but not with head circumference. The adjusted odds ratio for asthma in the previous two years in infants with a birth length of $56 \mathrm{~cm}$ or more was 6.4 (95\% CI 2.0 to 19.8$)$. Infants with a birth weight of less than $3.0 \mathrm{~kg}$ had an odds ratio for reported asthma of 0.2 (95\% CI $0.0-0.6)$. There were no significant associations of any of the birth parameters with skin prick positivity, reported hay fever, or eczema.

Conclusions-These results suggest that increased fetal growth is related to an increased risk of asthma and atopy in childhood. The precision of the findings is limited by the small numbers in the extreme categories of each birth parameter, but the results are consistent with intrauterine programming of the developing respiratory and immune systems. (Thorax 1999;54:905-910)

Keywords: fetal growth; birth weight; birth length; head circumference; atopy; asthma

The search for the factors involved in the apparent increase in asthma prevalence and severity worldwide is focusing increasingly on exposures in utero and in early infancy. In rela- tion to fetal growth, Godfrey et al reported an association between measures of head circumference at birth and serum $\operatorname{IgE}$ levels in adulthood. ${ }^{1}$ The risk of having an increased total $\mathrm{IgE}$ was four times greater in those with a head circumference greater than $35.5 \mathrm{~cm}$ at birth compared with those whose head circumference was $33 \mathrm{~cm}$ or less. Similarly, in a New Zealand birth cohort study a head circumference at birth of $37 \mathrm{~cm}$ or more was associated with a threefold risk of recurrent asthma by the age of 16 years. $^{2}$ In this cohort a large head circumference at birth was a stronger predictor of asthma in childhood than a positive family history. There were no clear associations between head circumference at birth and other measures of atopic status such as eczema or allergic rhinitis, or between gestational age or birth length and subsequent risk of asthma. A birth weight of less than $3.0 \mathrm{~kg}$ was associated with a decreased risk of recurrent asthma by 16 years of age. In both studies the interpretation was restricted by the limited clinical data available for analysis.

In this study we have investigated the association between anthropometric measurements at birth and the development in childhood of clinical asthma, and its immunological and physiological markers of atopy and airway hyperresponsiveness. The analysis is based on data from the Dunedin Multidisciplinary Health and Development Study ${ }^{3}$ which is ideally suited for this purpose, having extensive data on patient reported symptomatology and objective measures of lung function, airway hyperresponsiveness, serum IgE measurements, and skin prick testing during childhood. ${ }^{4}$

\section{Methods}

STUDY POPULATION

The Dunedin Multidisciplinary Child Development Study is a longitudinal birth cohort study of 1661 children born over one year from April 1972 at Queen Mary Maternity Hospital in Dunedin, New Zealand. ${ }^{3}$ Of this cohort, 1037 (91\% of those still living in the Otago Province) were enrolled at the age of three years and were seen every 2-3 years up to the age of 21 for a detailed medical and developmental assessment. Twins were excluded from the analyses because of the effect of multiple births on fetal growth. The perinatal measures of birth weight, length, head circumference, and gestation were collected from the hospital records. The family history of asthma and atopic disease was obtained from the accompanying adult (usually the mother) at seven years of age. A detailed questionnaire on past or 
present wheezing, diagnosis of asthma, use of anti-asthma medication, hospital admissions for asthma, and symptoms of eczema and hay fever was completed at ages nine, 11, and 13 years. ${ }^{5}$

Spirometric tests including measurements of forced expiratory volume in one second $\left(\mathrm{FEV}_{1}\right)$, forced vital capacity (FVC), and airway hyperresponsiveness by an abbreviated methacholine challenge were undertaken at ages nine, 11 , and 13 years. ${ }^{6}$ If the initial tests showed an $\mathrm{FEV}_{1} / \mathrm{FVC}$ of less than $75 \%$, methacholine challenge was not undertaken and the response to a bronchodilator was assessed instead.

Skin prick testing to 11 common allergens was performed at the age of 13 and total serum IgE concentration was measured at 11 years of age.

SUBJECTS

We chose to analyse the data at 13 years of age so that we could analyse symptom history and objective measures of atopy and airway hyperresponsiveness at the same age. At 13 years of age 1032 of the original 1037 enrolled sample were still alive and $734(71.2 \%)$ performed the respiratory assessment. Of these, 702 (68\%) underwent methacholine challenge while five $(0.7 \%)$ showed significant airway obstruction on the assessment day and were tested for bronchodilator response. Skin prick testing was performed in 714 children $(69.2 \%)$. Total serum IgE concentration was measured in 571 $(55.3 \%)$ at the age of 11 .

PERINATAL MEASURES

From the hospital medical records the following perinatal details were obtained: number of previous deliveries; gestation (weeks); birth weight (g); birth length and head circumference $(\mathrm{cm})$. From these data we also calculated the ponderal index (birth weight/length ${ }^{3}$ ) and a measure of relative head circumference (head circumference/ponderal index) which gives a measure of head size relative to the overall size of the infant. There were no statistically significant differences in the means and standard deviations of the birth parameters in those subjects who participated in the respiratory survey at the age of 13 and those who did not.

MEASURES OF ASTHMA AND ATOPY

In the questionnaire subjects were asked if they had ever had asthma or wheezy breathing and, if so, whether they had experienced these symptoms during the last two years and whether they were taking anti-asthma medication on an intermittent or regular basis. ${ }^{4}$ They were also asked whether they had ever had hay fever or eczema.

During the methacholine challenge the provoking concentration causing a $20 \%$ fall in $\mathrm{FEV}_{1}\left(\mathrm{PC}_{20} \mathrm{FEV}_{1}\right)$ was calculated by interpolation and airway hyperresponsiveness was defined as having a $\mathrm{PC}_{20}$ of $<8 \mathrm{mg} / \mathrm{ml}^{4}$ Subjects who did not perform the methacholine challenge because their initial $\mathrm{FEV}_{1} / \mathrm{FVC}$ was less than $75 \%$ and who showed a greater than $10 \%$ increase in $\mathrm{FEV}_{1}$ after nebulised albuterol
$(1.0 \mathrm{mg})$ were also considered to be hyperresponsive.

Skin prick testing was performed to $11 \mathrm{com}-$ mon allergens (Dermatophagoides pteronyssinus, grass, cat, dog, horse, kapok, wool, Aspergillus fumigatus, Alternaria, Penicillium and Cladosporium). A positive response was defined as one or more positive skin prick tests with a maximum weal diameter at least $2 \mathrm{~mm}$ greater than the negative control. ${ }^{7}$

The serum total $\operatorname{IgE}$ was measured at 11 years of age. The serum was separated within one hour of collection and frozen at $-20^{\circ} \mathrm{C}$. The serum total IgE level was measured in duplicate by the Phadebas paper radioimmunosorbent test (PRIST) technique; if the duplicate measurements were not within $10 \%$ of one another, the assays were repeated. Duplicate measurements of the serum $\operatorname{IgE}$ were averaged and the mean absolute $\operatorname{IgE}$ was used in the analysis. ${ }^{8}$ There were no statistically significant differences with respect to birth parameters or prevalence of asthma between those who did and those who did not have serum IgE measurements.

\section{DATA ANALYSIS}

The continuous birth parameters were initially divided into five categories. These were approximately quintiles, but the categories were "rounded" for simplicity of presentation and interpretation; the non-continuous data were categorised depending on the variable. The birth anthropometric measures were then categorised into low, medium and high, and odds ratios were calculated using the middle category as the reference. The data were analysed using the SAS program ${ }^{9}$ and odds ratios were adjusted for potential confounders including gestational age, maternal age, maternal smoking during pregnancy, socioeconomic status, and parental history of asthma using logistic regression. ${ }^{10}$ Despite the number of confounders adjusted for, the regression model remained stable with little increase observed in the standard errors for key variables compared with the univariate analyses. The $\mathrm{p}$ values for the trends in odds ratio for continuous variables were calculated using the continuous data.

\section{Results}

Table 1 shows the prevalences of reported asthma and other clinical outcomes in the categories of the various perinatal measures and table 2 shows the odds ratios, adjusted for potential confounders, obtained by categorising the birth parameters into low, medium, and high values.

ASTHMA SYMPTOMS AND DIAGNOSED ASTHMA

The most striking association between reported asthma and a birth anthropometric measure was found for birth length. There was a relatively linear increase in reported asthma as the birth length increased. Infants with a birth length greater than $56 \mathrm{~cm}$ (95th percentile) had an adjusted odds ratio of 6.4 (95\% CI 2.0 to 19.8 ) for reported asthma by the age of 13 years, 3.9 (95\% CI 1.1 to 13.4 ) for asthma 
Table 1 Prevalence of asthma and atopy outcomes within the different categories of birth parameter

\begin{tabular}{|c|c|c|c|c|c|c|c|}
\hline & No. & $\begin{array}{l}\text { Ever } \\
\text { asthma }\end{array}$ & $\begin{array}{l}\text { Drug } \\
\text { therapy }\end{array}$ & $\begin{array}{l}\text { Asthma } \\
\text { in past } 2 \\
\text { years }\end{array}$ & $B H R$ & $\begin{array}{l}\operatorname{IgE} E \\
\geqslant 150 \\
I U^{\star}+\end{array}$ & $\begin{array}{l}\text { Skin test } \\
+ \text { ve (weal } \\
\geqslant 2 \mathrm{~mm})\end{array}$ \\
\hline \multicolumn{8}{|c|}{ Birth length $(\mathrm{cm})$} \\
\hline$<50$ & 103 & 6.9 & 7.8 & 4.9 & 6.3 & 46.5 & 35.9 \\
\hline $50-51.9$ & 210 & 15.2 & 14.3 & 12.4 & 8.6 & 45.2 & 47.9 \\
\hline $52-53.9$ & 267 & 12.0 & 12.4 & 10.5 & 8.1 & 38.8 & 45.6 \\
\hline $54-55.9$ & 120 & 18.3 & 17.5 & 17.5 & 9.6 & 46.7 & 49.2 \\
\hline $56+$ & 34 & 32.4 & 23.5 & 20.6 & 9.7 & 37.5 & 40.6 \\
\hline \multicolumn{8}{|c|}{ Head circumference $(\mathrm{cm})$} \\
\hline$<34$ & 154 & 9.7 & 9.1 & 7.1 & 6.3 & 43.0 & 37.0 \\
\hline $34-34.9$ & 197 & 13.2 & 14.7 & 12.2 & 9.0 & 39.2 & 49.0 \\
\hline $35-35.9$ & 223 & 16.3 & 13.9 & 13.1 & 7.9 & 42.9 & 43.7 \\
\hline $36-36.9$ & 111 & 18.0 & 18.0 & 16.2 & 8.3 & 41.1 & 52.7 \\
\hline $37+$ & 49 & 14.3 & 12.2 & 10.2 & 13.0 & 61.4 & 46.8 \\
\hline \multicolumn{8}{|c|}{ Birth weight (kg) } \\
\hline$<2.5$ & 35 & 2.9 & 5.7 & 2.9 & 10.3 & 60.0 & 48.6 \\
\hline $2.5-2.9$ & 115 & 6.1 & 6.1 & 4.4 & 4.6 & 41.7 & 36.5 \\
\hline $3.0-3.4$ & 269 & 20.5 & 19.0 & 17.2 & 10.5 & 41.0 & 50.6 \\
\hline $3.5-3.9$ & 232 & 11.2 & 12.9 & 9.9 & 8.4 & 45.7 & 45.6 \\
\hline $4.0+$ & 84 & 17.9 & 11.9 & 14.3 & 4.9 & 37.8 & 38.3 \\
\hline \multicolumn{8}{|c|}{ Relative head circumference $\ddagger$} \\
\hline$<125$ & 33 & 12.1 & 12.1 & 12.1 & 9.4 & 33.3 & 30.3 \\
\hline $125-138.9$ & 185 & 11.5 & 9.7 & 8.2 & 6.3 & 46.8 & 44.9 \\
\hline $139-151.9$ & 296 & 13.5 & 13.5 & 11.5 & 8.1 & 38.9 & 44.8 \\
\hline $152-164.9$ & 161 & 16.2 & 16.2 & 14.9 & 9.9 & 45.5 & 45.0 \\
\hline $165+$ & 59 & 22.0 & 20.3 & 17.0 & 10.9 & 53.5 & 57.6 \\
\hline \multicolumn{8}{|c|}{ Gestational age (weeks) } \\
\hline$<37$ & 28 & 10.7 & 10.7 & 10.7 & 8.0 & 57.1 & 50.0 \\
\hline $37-37.9$ & 23 & 13.0 & 13.0 & 13.0 & 13.0 & 52.6 & 65.2 \\
\hline $38-39.9$ & 209 & 13.0 & 12.0 & 11.0 & 8.0 & 39.2 & 42.7 \\
\hline $40-40.9$ & 209 & 16.8 & 16.8 & 13.4 & 7.5 & 43.3 & 49.3 \\
\hline $41+$ & 183 & 15.4 & 12.6 & 12.6 & 9.0 . & 45.8 & 42.8 \\
\hline \multicolumn{8}{|l|}{ Older siblings } \\
\hline 0 & 246 & 16.3 & 15.0 & 14.3 & 9.8 & 39.1 & 47.4 \\
\hline 1 & 216 & 14.0 & 13.9 & 11.1 & 7.3 & 44.5 & 47.1 \\
\hline 2 & 122 & 13.9 & 11.5 & 10.7 & 8.9 & 41.5 & 45.4 \\
\hline $3+$ & 151 & 11.3 & 12.6 & 9.9 & 6.8 & 49.1 & 39.3 \\
\hline \multicolumn{8}{|l|}{ Sex } \\
\hline Female & 355 & 10.2 & 9.9 & 8.7 & 6.2 & 39.2 & 37.8 \\
\hline Male & 380 & 17.9 & 17.1 & 14.8 & 10.2 & 46.4 & 52.3 \\
\hline
\end{tabular}

${ }^{\star} \operatorname{IgE}$ measured at age 11 years.

†Number differs from age 13 years.

$\ddagger$ Head circumference/ponderal index.

in the past two years, and 4.6 (95\% CI 1.4 to 15.7) for using anti-asthma medication compared with infants with a birth length of $50-55 \mathrm{~cm}$.

As previously reported, ${ }^{4}$ a negative association between birth weight and reported asthma was apparent for birth weights of less than $3.0 \mathrm{~kg}$. The adjusted odds ratio for reported asthma in those with a birth weight of less than $3.0 \mathrm{~kg}$ was 0.2 (95\% CI 0.0 to 0.6 ) compared with those with a birth weight of more than $3.0 \mathrm{~kg}$. In subjects with a birth weight of less than $3.0 \mathrm{~kg}$ there was also a significantly reduced prevalence of use of antiasthma medication and reported asthma in the past two years.

Subjects in the group with the smallest head circumference $(<34 \mathrm{~cm})$ had a reduced prevalence of reported asthma, but there was no significant trend for increasing prevalence in those with a larger head circumference. Those with the largest relative head circumference had a greater prevalence of reported asthma, although this did not reach statistical significance (not shown in tables).

We therefore considered the independent and joint effects of these various birth measures with regard to the clinical markers of asthma and atopy (table 3). Increasing birth length was associated with an increased prevalence of asthma and wheeze within each category of head circumference or relative head circumference. Within each category of birth length, the prevalence of asthma tended to increase as the relative head circumference increased, suggesting that the effect of relative head circumference was independent of the birth length effect. Increasing absolute head circumference was not associated with an increased prevalence of asthma and wheeze within each category of birth length.

\section{BRONCHIAL HYPERRESPONSIVENESS}

The prevalence of airway hyperresponsiveness increased as birth length increased but when the other variables, particularly birth weight, were adjusted for (table 1), this trend did not reach statistical significance. The unadjusted prevalence of airway hyperresponsiveness showed an increase in those with a head circumference of more than $37 \mathrm{~cm}$ (table 1) but, after adjustment for the other variables, this was not statistically significant (table 2). The cross tabulations in table 3 show that the prevalence of airway hyperresponsiveness tends

Table 2 Adjusted prevalence odds ratios for asthma and atopy outcomes between the categories of birth parameters with the middle category being used as the reference

\begin{tabular}{|c|c|c|c|c|c|c|c|}
\hline & No. & $\begin{array}{l}\text { Ever asthma } \\
\text { OR }(95 \% \mathrm{CI})\end{array}$ & $\begin{array}{l}\text { Drug therapy } \\
\text { OR }(95 \% \text { CI) }\end{array}$ & $\begin{array}{l}\text { Asthma in past } 2 \\
\text { years OR }(95 \% \text { CI) }\end{array}$ & $\begin{array}{l}\text { BHR OR } \\
(95 \% \text { CI) }\end{array}$ & $\begin{array}{l}I g E \geqslant 150 I U^{\star} \\
O R(95 \% C I)\end{array}$ & $\begin{array}{l}\text { Skin test }+ \text { ve (weal } \geqslant 2 \\
m m) \text { OR }(95 \% \mathrm{CI})\end{array}$ \\
\hline \multicolumn{8}{|l|}{ Birth length (cm) } \\
\hline$<50$ & 103 & $1.0 \quad(0.3$ to 3.3$)$ & $1.4(0.4$ to 4.4$)$ & $1.0(0.3$ to 3.7$)$ & $1.0(0.3$ to 3.4$)$ & $1.0(0.5$ to 2.3$)$ & 0.7 (0.4 to 1.5$)$ \\
\hline $50-55.9$ & 597 & 1.0 & 1.0 & 1.0 & 1.0 & 1.0 & 1.0 \\
\hline$\geqslant 56$ & 34 & $6.4(2.0$ to 19.8$)$ & $4.6 \quad(1.4$ to 15.7$)$ & $3.9(1.1$ to 13.4$)$ & $0.8 \quad(0.1$ to 6.6$)$ & $0.8 \quad(0.2$ to 2.5$)$ & $1.1 \quad(0.4$ to 2.7$)$ \\
\hline $\mathrm{p}$ value for trend & 734 & 0.05 & 0.11 & 0.04 & 0.56 & 0.42 & 0.75 \\
\hline \multicolumn{8}{|c|}{ Head circumference $(\mathrm{cm})$} \\
\hline$<34$ & 154 & 1.7 (0.8 to 3.9$)$ & 1.5 (0.7 to 3.5$)$ & $1.4(0.6$ to 3.4$)$ & $1.0 \quad(0.3$ to 2.7$)$ & $1.0(0.5$ to 1.9$)$ & $0.5(0.3$ to 1.0$)$ \\
\hline $34-36.9$ & 531 & 1.0 & 1.0 & 1.0 & 1.0 & 1.0 & 1.0 \\
\hline$\geqslant 37$ & 49 & $0.2(0.1$ to 0.9$)$ & $0.4 \quad(0.1$ to 1.6$)$ & $0.1 \quad(0.0$ to 0.9$)$ & $0.9(0.2$ to 4.3$)$ & $3.4(1.4$ to 7.9$)$ & $1.2(0.6$ to 2.8$)$ \\
\hline $\mathrm{p}$ value for trend & 734 & 0.86 & 0.91 & 0.67 & 0.26 & 0.02 & 0.75 \\
\hline \multicolumn{8}{|l|}{ Birth weight (kg) } \\
\hline$<3.0$ & 150 & $0.2 \quad(0.0$ to 0.6$)$ & $0.1 \quad(0.0$ to 0.5$)$ & $0.2(0.0$ to 0.6$)$ & $0.8 \quad(0.3$ to 2.6$)$ & $0.9 \quad(0.4$ to 1.9$)$ & $0.9 \quad(0.5$ to 1.8$)$ \\
\hline $3.0-3.9$ & 501 & 1.0 & 1.0 & 1.0 & 1.0 & 1.0 & 1.0 \\
\hline$\geqslant 4.0$ & 84 & $1.0 \quad(0.4$ to 2.4$)$ & $0.5 \quad(0.2$ to 1.4$)$ & $1.2(0.5$ to 3.0$)$ & $0.4 \quad(0.1$ to 1.6$)$ & $0.6(0.3$ to 1.2$)$ & $0.6(0.3$ to 1.2$)$ \\
\hline $\mathrm{p}$ value for trend & 735 & 0.70 & 0.34 & 0.69 & 0.24 & 0.49 & 0.47 \\
\hline \multicolumn{8}{|l|}{ Older siblings } \\
\hline 0 & 246 & 1.0 & 1.0 & 1.0 & 1.0 & 1.0 & 1.0 \\
\hline $1-2$ & 338 & $0.7 \quad(0.4$ to 1.2$)$ & $0.8 \quad(0.5$ to 1.5$)$ & $0.6 \quad(0.3$ to 1.2$)$ & $1.0(0.5$ to 2.2$)$ & 1.3 (0.8 to 2.0$)$ & 0.9 (0.6 to 1.4$)$ \\
\hline $3+$ & 151 & $0.3(0.1$ to 0.8$)$ & $0.5 \quad(0.2$ to 1.3$)$ & $0.4 \quad(0.2$ to 1.1$)$ & $0.6(0.2$ to 1.9$)$ & $2.3(1.2$ to 4.6$)$ & $0.7 \quad(0.4$ to 1.3$)$ \\
\hline $\mathrm{p}$ value for trend & 735 & 0.02 & 0.09 & 0.07 & 0.35 & 0.14 & 0.24 \\
\hline \multicolumn{8}{|l|}{ Sex } \\
\hline Female & 355 & 1.0 & 1.0 & 1.0 & 1.0 & 1.0 & 1.0 \\
\hline Male & 380 & $1.8(1.0$ to 3.0$)$ & $1.7 \quad(1.0$ to 2.9$)$ & $1.8(1.0$ to 3.1$)$ & $1.4(0.7$ to 2.6$)$ & $1.3(0.9$ to 1.9$)$ & $1.4(1.0$ to 2.0$)$ \\
\hline
\end{tabular}

The analyses are adjusted for all variables listed in the table (gestational age, maternal smoking, socioeconomic status, and parental history of asthma). 
Table 3 Cross tabulations of birth length vs head circumference and relative head circumference for asthma and bronchial hyperresponsiveness (BHR) at age 13, and increased IgE levels at age 11

\begin{tabular}{|c|c|c|c|}
\hline & \multicolumn{3}{|c|}{ Prevalence \% (No.) } \\
\hline \multicolumn{4}{|l|}{ Ever asthma } \\
\hline & \multicolumn{3}{|c|}{ Head circumference $(\mathrm{cm})$} \\
\hline Birth length $(\mathrm{cm})$ & $<34$ & $34-36.9$ & $37+$ \\
\hline$<50$ & $6.6 \%(76)$ & $8.0 \%(25)$ & $(0)$ \\
\hline $50-55.9$ & $12.8 \%(78)$ & $14.8 \%(480)$ & $12.8 \%(39)$ \\
\hline \multirow[t]{2}{*}{$56+$} & $(0)$ & $37.5 \%(24)$ & $20.0 \%(10)$ \\
\hline & \multicolumn{3}{|c|}{ Relative head circumference } \\
\hline Birth length $(\mathrm{cm})$ & $<125$ & $125-164.9$ & $165+$ \\
\hline$<50$ & $12.5 \%(8)$ & $5.8 \%(87)$ & $16.7 \%(6)$ \\
\hline $50-55.9$ & $12.0 \%(25)$ & $14.1 \%(533)$ & $20.5 \%(39)$ \\
\hline $56+$ & (0) & $35.0 \%(20)$ & $28.6 \%(14)$ \\
\hline \multicolumn{4}{|l|}{$B H R$} \\
\hline & \multicolumn{3}{|c|}{ Head circumference $(\mathrm{cm})$} \\
\hline Birth length $(\mathrm{cm})$ & $<34$ & $34-36.9$ & $37+$ \\
\hline$<50$ & $4.3 \%(70)$ & $11.5 \%(26)$ & $(0)$ \\
\hline $50-55.9$ & $8.3 \%(72)$ & $8.4 \%(463)$ & $10.5 \%(38)$ \\
\hline $56+$ & $(0)$ & $4.4 \%(23)$ & $25.0 \%(8)$ \\
\hline \multicolumn{4}{|l|}{$\operatorname{IgE} \geqslant 150 \mathrm{IU}$} \\
\hline & \multicolumn{3}{|c|}{ Head circumference $(\mathrm{cm})$} \\
\hline Birth length $(\mathrm{cm})$ & $<34$ & $34-36.9$ & $37+$ \\
\hline$<50$ & $43.6 \%(55)$ & $56.3 \%(16)$ & (0) \\
\hline $50-55.9$ & $42.4 \%(59)$ & $40.9 \%(381)$ & $63.9 \%(36)$ \\
\hline $56+$ & $(0)$ & $31.3 \%(16)$ & $50.0 \%(8)$ \\
\hline
\end{tabular}

to increase as head circumference increases within each length category.

ATOPY, SERUM IGE, ECZEMA, AND HAY FEVER

There were no significant associations between the prevalence of reported eczema or hay fever by 13 years of age and any of the birth parameters (not shown in tables). There was a reduced prevalence of reported hay fever with an increasing number of older siblings. The odds ratio for reported hay fever in those infants with three or more older siblings was 0.4 (95\% CI 0.2 to 0.7$)$ compared with those with 1-2 older siblings.

There was a significant trend for those infants with a larger head circumference at birth to have a raised serum total $\operatorname{IgE}$ at the age of 11. Infants with a head circumference greater than $37 \mathrm{~cm}$ had an odds ratio for increased total $\operatorname{IgE}$ of 3.4 (95\% CI 1.4 to 7.9 ) compared with those with a head circumference of 34-37 cm. There were no other statistically significant trends in birth parameters in relation to total IgE concentration and, in particular, increasing birth length was not associated with an increased total $\operatorname{IgE}$.

The presence of atopy, as defined by a positive response to skin prick testing, was reduced in those infants with a small head circumference at birth. Infants with a head circumference of less than $34 \mathrm{~cm}$ had an odds ratio of 0.5 (95\% CI 0.3 to 1.0 ) for atopy compared with those with a head circumference of $34-37 \mathrm{~cm}$. The presence of atopy tended to increase as the relative head circumference increased, but this was not statistically significant. There were no other significant trends in relation to birth parameters and atopy on skin prick testing. When the skin prick response to house dust mite alone was analysed there was no significant change in our results.

\section{Discussion}

There is considerable epidemiological evidence to suggest that perinatal events may predispose to the risk of developing chronic disorders in adulthood. The initial work by Barker et al found that adults who had low weight, small head size and small length at birth subsequently had considerably higher rates of ischaemic heart disease, hypertension, impaired glucose tolerance, and hypercholesterolaemia. ${ }^{11}$ These findings led to the concept of "programming" in which it was proposed that an early stimulus or insult at a critical period of development could lead to permanent or long term changes to the structure or function of an organ system. Subsequent studies have reported an association between birth parameters and conditions as variable as polycystic ovarian disease, ${ }^{12}$ cerebrovascular disease, and chronic obstructive airways disease. ${ }^{13}$

This study is one of the first to analyse in detail the relationship between birth anthropometric measures and the subsequent development of asthma and atopy. While these findings should be interpreted with some caution due to the large number of comparisons involved, they are generally consistent in that they show a positive correlation between size at birth and subsequent risk of asthma and atopy in childhood. The main findings were that low birth weight was associated with a lower prevalence of reported asthma at 13 years of age while greater birth length was associated with an increased prevalence of reported asthma. A large head circumference at birth was associated with increased total $\operatorname{IgE}$ at 11 years of age and a small head circumference was associated with a reduction in the presence of atopy on skin prick testing.

Our findings in relation to low birth weight are in contrast to some other studies that have found low birth weight to be associated with an increased risk of asthma. In a Norwegian population based study they found an inverse association between birth weight and number of respiratory symptoms, but there was a weak positive association with increasing birth length. ${ }^{14}$ In part, the different findings may relate to the age at which the relationship is examined, as the presence of wheeze in early infancy may be reflecting airway size rather than asthma. ${ }^{15}$ It may also relate to confounding by other factors, as occurred in a study of perinatal risk factors for asthma in inner city AfroAmericans in which the association between low birth weight and childhood asthma was no longer significant when the variables of maternal smoking, prematurity, and lack of prenatal care were adjusted for. ${ }^{16}$ In this particular cohort there were only 28 infants $(4.2 \%)$ born at less than 37 weeks gestation and there were no gestational effects seen on prevalences for ever asthma, current asthma, or the measures of atopy. With respect to birth weight, the findings reported here are consistent with another major New Zealand cohort study in which infants with a birth weight of less than $3.0 \mathrm{~kg}$ had a relative risk of $0.6(95 \%$ CI 0.36 to 0.95 ) for recurrent asthma at 16 years of age. ${ }^{2}$

In our analyses the most striking association was between that of birth length and asthma. Those infants who were longer than $56 \mathrm{~cm}$ at 
birth (95th centile) had an odds ratio for reported asthma of 6.4 (95\% CI 2.0 to 19.8) compared with those with a birth length of $50-56 \mathrm{~cm}$. Infants who were longer at birth also reported more asthma and wheeze over the preceding two years at the age of 13 and were more likely to be taking anti-asthma medication at 13 years of age. Increasing birth length was also associated with a tendency towards an increased risk of bronchial hyperresponsiveness, but not for having an increased total $\mathrm{IgE}$ at age 11 years or being atopic on skin prick testing at age 13 years. This lack of association between birth length and measures of atopy was unexpected in view of the strength of the association between birth length and asthma observed in this study and the relationship between serum total IgE and asthma previously reported by Sears et al. ${ }^{8}$ However, there is increasing evidence that the increasing prevalence of atopic sensitisation only partly explains the increasing prevalence of asthma and that we need to consider other risk factors and mechanisms to explain fully the changing epidemiology of asthma. ${ }^{17}$

A head circumference of more than $37 \mathrm{~cm}$ (95th centile) at birth was associated with a greatly increased risk of having an increased total IgE at 11 years of age. The relationship was non-linear and was associated with a step up in prevalence in those with a head circumference of more than $37 \mathrm{~cm}$. A similar pattern was also observed for airway hyperresponsiveness in the unadjusted results but, when birth weight was taken into account, the effect was not statistically significant. These IgE findings are consistent with those previously reported by Godfrey et al. However, the lack of a strong association between head circumference and reported asthma is not in keeping with our previous findings from the Christchurch longitudinal study. ${ }^{2}$ We did not see any association between head circumference at birth and the clinical parameters of hay fever and eczema, but there was a reduction in atopy on skin prick testing in those infants with a small head circumference at birth.

The effect of birth size on the prevalence of asthma was only observed at the extremes of the parameters rather than as a linear relationship. However, this may reflect the physiological mechanism at work rather than a lack of strength for the association. The reasons for the association between increased fetal growth and the subsequent risk of asthma and atopy are unclear and were not addressed in this study. However, it is known that fetal growth is determined by many different factors including maternal health and nutrition, placental function, and fetal growth potential. These factors may also interact to influence the developing respiratory and immune systems and programme the fetus to be at greater risk of developing asthma and atopy in later childhood. Alternatively, it is possible that the fetal growth patterns are a marker for some other risk factor to which the infant is exposed in later life. Barker's hypothesis in relation to hypertension and ischaemic heart disease postulated that relative fetal undernutrition leads to program- ming of the fetus to be at increased risk for these diseases in adulthood. Our data suggest that relative undernutrition may be protective while overnutrition increases the risk for asthma and atopy in later childhood.

It is interesting to note that there have been secular trends of increasing fetal growth throughout the world in recent decades, particularly as populations become more affluent. ${ }^{18-24}$ This raises the hypothesis that factors responsible for these secular trends could have contributed to the worldwide variation and increase over recent decades in the prevalence of asthma and atopy. ${ }^{25}$

In summary, we have attempted to investigate further the relationship between fetal growth and the subsequent development of asthma and atopic disease in later childhood. Our findings suggest that smaller infants are at reduced risk of developing asthma and that, as the size of the infant at birth increases, so does their risk for subsequently developing asthma and atopy. This study is limited by the small numbers in the extreme categories of birth parameters and the significance of the findings would be strengthened by being repeated in a larger population. The mechanisms responsible for these associations require further investigation. This work was supported by a grant from the Guardian Trust
(Trustee of the David and Cassie Anderson Memorial Trust) and Glaxo Wellcome New Zealand Ltd. The Wellington Asthma Research Group is also supported by a Programme Grant from Research Group is also supported by a Programme Grant from the Health Research Council of New Zealand. The Dunedin Multidisciplinary Health and Development Unit is supported by the Health Research Council of New Zealand. The studies of development of asthma in this cohort were supported by the Health Research Council of New Zealand and the Otago Medical Research Foundation.

1 Godfrey KM, Barker DJP, Osmond C. Disproportionate fetal growth and raised IgE concentration in adult life. Clin Exp Allergy 1994;24:641-8.

2 Fergusson D, Crane J, Beasley R, et al. Perinatal factors and atopic disease in childhood. Clin Exp Allergy 1997;27: 1394-401.

3 Silva PA, Stanton WR, eds. From child to adult: the Dunedin Multidisciplinary Health and Development Study. Auckland: Oxford University Press, 1996.

4 Sears MR, Holdaway MD, Flannery EM, et al. Parental and neonatal risk factors for atopy, airway hyperresponsiveness, and asthma. Arch Dis Child 1996;75: 392-8.

5 Jones DT, Sears MR, Holdaway MD, et al. Childhood asthma in New Zealand. Br $\mathcal{F}$ Dis Chest 1987;81:332-40.

6 Sears MR, Jones DT, Holdaway MD, et al. Prevalence of bronchial reactivity to inhaled methacholine in New bronchial reactivity to inhaled methach
Zealand children. Thorax 1986;41:283-9.

7 Sears MR, Herbison GP, Holdaway MD, et al. The relative risk of sensitivity to grass pollen, house dust mite and cat dander in the development of childhood asthma. Clin Exp Allergy 1989;19:419-24.

8 Sears MR, Burrows B, Flannery EM, et al. Relation between airway responsiveness and serum IgE in children with asthma and in apparently normal children. $N$ Engl f Med 1991;325:1067-71.

9 Carey NC. SAS Language Guide for personal computers. SAS Institute, 1988 .

10 Harrell F. The Logist procedure. In: $S A S$ supplemental library user's guide. Cary, NC: SAS Institute, 1983.

11 Barker D, Osmond C, Simmonds S, et al. The relation of small head circumference and thinness at birth to the death from cardiovascular disease in adult life. $B M \mathcal{F} 1993 ; 306$ 422-6.

12 Cresswell J, Barker D, Fraser R. Fetal growth, length of gestation, and polycystic ovaries in adult life. Lancet 1997;350 1131-5.

13 Barker D, Godfrey K, Shaheen S. Relation of birth weight and childhood respiratory infection to adult lung function and death from chronic obstructive airways disease. $B M \mathcal{F}$ 1991;303:671-5.

14 Svanes C, Omenaas E. Birth characteristics and asthma symptoms in young adults: results from a population-based cohort study in Norway. Eur Respir f 1998;12:1366-70.

15 Martinez F, Wright A, Taussig L. Asthma and wheezing in the first six years of life. N Engl f Med 1995;332:133-8. 
16 Oliveti J, Kercsmar C, Redline S. Pre and perinatal risk factors for asthma in inner city African-American children. Am f Epidemiol 1996;143:570-7.

17 Pearce N, Pekkanen J, Beasley R. How much asthma is really attributable to atopy? Thorax 1999;54:268-72.

18 Bakwin $\mathrm{H}$. The secular change in growth and development. Acta Paediatr Scand 1963;53:79-89.

19 Power C. National trends in birth weight: implications for future adult disease. $B M F$ 1994;308:1270-1.

20 Nishida H, Sakanoue M. New fetal growth curves for Japanese. Acta Paediatr Scand 1985;319:62-7.

21 Ousted M, Scott A. Head circumference charts updated. Arch Dis Child 1985;60:936-9.
22 Tonkin S. The Tokelau Islands Children's Study: atoll and New Zealand comparisons: physical growth. NZ Med f 1979;89:429-32.

23 Popkin B. The nutrition transition in low-income countries: an emerging crisis. Nutr Rev 1994;52:285-98.

24 Keeley DJ, Neill P, Gallivan S. Comparison of the prevalence of reversible airways obstruction in rural and urban Zimbabwean children. Thorax 1991;46:549-53.

25 National Heart, Lung and Blood Institute, National Institutes of Health. Global strategy for asthma management and prevention. NHLBI/WHO Workshop Report. Publication No. 95-3659. 1995: 10-24. 